\title{
INVESTIGATING READABILITY OF TEXTS FROM THE PERSPECTIVE OF DISCOURSE ANALYSIS
}

\author{
Mochamad Rizqi Adhi Pratama ${ }^{1}$ \\ 1'(Universitas Ngudi Waluyo/mochamadrizqi89@gmail.com) \\ Akbar Syahbana ${ }^{2}$ \\ ${ }_{2}^{2}$ (Universitas Negeri Semarang/syahbana.akbar@gmail.com)
}

\begin{abstract}
Investigating readability of texts for use in teaching reading becomes crucial as teachers should adjust the readability of the texts to suit the level of students' reading skill. If the students learn the inappropriate level of readability of reading texts, it might decrease the success of teaching reading or even the learning of reading might be absent. This paper is aimed at investigating how to analyze readability of the texts in the perspective of discourse analysis; thus, English teachers can choose and apply the appropriate texts as the teaching materials for their students. The objects of this study are three different texts about butterflies taken from three different sources. The study employed descriptive qualitative with concerning the all aspects of the texts which contribute to the readabilities of the texts using Gerot and Wignell (1995) and Eggins' (2004) theories. Based on the result, there are three central elements of the texts which substantially contribute to the texts' readabilities such as technical terms, noun phrases, and finiteness. Finally, it is suggested that the teachers analyze the three elements of texts as the consideration in adjusting the texts' level of readabilities with the students' level of reading skills.
\end{abstract}

Keywords:

Texts Readabilities, Discourse Analysis

DOI: $10.19105 /$ ojbs.v12i2.1894

\section{A. Introduction}

In the English Language Teaching (ELT), instead of the teachers, teaching materials play important roles for the success of the teaching and learning process. Model of texts as the one of the most familiar teaching materials has become a central point in teaching with various texts. According to Habibullah, the determination of choosing texts should be based on who the students are. ${ }^{1}$ In this present study, we discussed how to investigate three different texts about butterflies by employing discourse analysis as the knife of analysis. Knowing the complexity of texts is useful for teachers because they can design three important components of literacy instruction: building skills, establishing

1 Mosleh Habibullah, "Techniques in Teaching Reading Comprehension," OKARA: Jurnal Bahasa Dan Sastra 6, no. 2 (2012): 8, http://dx.doi.org/10.19105/ojbs.v6i2.431. 
purpose, and fostering motivation. ${ }^{2}$ In a short, it is aimed at understanding what elements of the texts which substantially contribute to the texts' readabilities when a text is seen from the perspective of discourse studies.

Besides, this study needs to be done inasmuch as there are many textbooks or workbooks presenting texts which are too advanced for the students. It is because most of the books only adopt the text from science or popular science websites, online magazines, online newspapers, or other sources without any adaptation or adjustment to the texts' readabilities. This will give impact on the students' abilities to understand the text and possibly this will end up with students' frustration. This phenomenon does need teachers' attention as it will determine the success of students in achieving competence especially in reading skills. ${ }^{3}$ For example, the teachers can choose an appropriate text related to the students' level of reading skill.

The problem investigated in this study relates to know what the texts' elements contribute to the texts' readabilities seen from the perspective of discourse analysis. Of course, the result of this study can help the teachers to

\footnotetext{
2 Timothy Shanahan, Douglas Fisher, and Nancy Frey, "The Challenge of Challenging Text," Reading: The Core Skill 69, no. 2 (March 2012): 58-62.

3 Nuriyatul Hamidah, "Story Grammar Strategy: An Approach to Teach Reading Narrative Text," OKARA: Jurnal Bahasa Dan Sastra 10, no. 1 (2016): 44-53, http://dx.doi.org/10.19105/ojbs.v10i1.810.
}

adjust texts based on the students' level of reading skill. Thus, the writers conducted the study entitled "Investigating Readability of Texts from the Perspective of Discourse Analysis" in order to understand and know more about the texts' elements contributing to the texts' readability.

This point started with how a written language differs from spoken one. Written language is not simply speech written down. It is different because it evolves to serve different function. Written language tends to be more independent of its immediate context while spoken language tends to be more context dependent. ${ }^{4}$

In written language, the author of texts should know that is language as a reflection. According to Hinkel, ${ }^{5}$ "the characteristics of written language are context independent, language as reflection, language as product, monologic organization, and synoptic structure". It means those can make a different with spoken language because the author should have a good knowledge to write for many people. Then, creating a good context is a must because in spoken language is easy to tell what we mean. Otherwise, we have to use a variety of words in writing form, a simple explanation in order to make a reader be interested in with our product in written language.

\footnotetext{
4 Scott Thornbury, How to Teach Speaking (London: Pearson Educational Limited, 2005), 63.

5 Eli Hinkel, Teaching English Grammar to Speakers of Other Languages (New York: Routledge, 2016), 92.
} 
Instead of the function, written language is also equipped with several specific features. While spoken language employs everyday lexis, written language employs prestige lexis. That is why in written language, we often come across a number of technical terms specialized for a particular field. In line with Eggins, ${ }^{6}$ the complexity of texts can be measured by checking the combination of noun phrases used.

However, in terms of grammatical features, written language employs grammatical simplicity while spoken language employs grammatical complexity. It shows that the grammatical features of a written text are less complex than that of spoken language. The author can express the content of texts by using modalization and modulation related to the finiteness. In terms of lexical density, written language is seen to be lexically dense while spoken language is lexically sparse. It is defined as the measure of the amount of content information in a clause or in a text. ${ }^{7}$ From several features above, which one seems to be the feature much contributing to the readability of written language.

\section{B. Method}

This study employed descriptive qualitative approach because it just

6 Suzanne Eggins, Introduction to Systemic Functional Linguistics, 2nd ed. (London: Continuum, 2004), 35.

${ }^{7}$ Linda Gerot and Peter Wignell, Making Sense of Functional Grammar (Cammeray: Antipodean Educational Enterprises, 1995), 165. focused on the three texts about butterflies taken from three different sources. For analysis, we used qualitative method, but quantitative data is needed to support in data analysis. There is no statistical process because Sugiyono said that "qualitative has the natural setting as the direct resource of data and the researcher is the key instrument". 8

As details, the texts are taken from different sources and levels such as wikipedia.org, popsci.com (popular science), and enesainenglish.blogspot.co.id (narrative text). It means that those texts showed the different result in terms of readability texts. Several steps are done to analyze data: (1) reading the texts, (2) identifying and classifying the texts' elements, (3) counting the findings, (4) interpreting the results, and (5) drawing the conclusion and suggestion.

\section{Results}

In this part, we explained the results of each text of butterflies because it is needed to use a simple form in explanation to answer the problem of this study. After that, the discussion was related to the several points of readability features which have mentioned in previous section such as technical terms, lexical density and clause complex.

8 Sugiyono, Metode Penelitian Kuantitatif, Kualitatif Dan $R \& D$ (Bandung: Alfabeta, 2013), 13. 


\section{Wikipedia.org}

\section{a. Technical terms}

When we look at the first text, it seems that it will be hard for us to comprehend the whole text if we are not scientifically knowledgeable especially in Biology. We come across several words such as mimicry, superfamily Hesperioidea, aposematism, and Hedyloidea which make this text specialized for particular readers. As a result, a common reader will find it hard to grasp every piece of information the text tried to provide. Here are the technical terms employed by the writer in the text.

Those mentioned words are not commonly heard by common people as they do not exist in everyday vernacular. That is why, in order to understand the text, it needs special schemata dealing with science in Biology.

The existence of technical terms employed helps us assume who the writer is and who the readers are. The employed technical terms represent the writer's knowledgeability and expertise especially in science about butterfly. In other words, the writer is someone who is expert in the field. Then, the writer tries to address readers who are also involved in this field. They can be teacher, lecturer, scientist, or students.
The writer employed those technical terms also in purpose to create in a detailed way a text called report text in which, in this case, the text tells the reader what butterflies are in general. However, this text is equipped with detailed information by displaying technical terms which require special knowledge of the reader.

\section{b. Noun phrases}

When we look at how the phrases are constructed to build sentences, we can see that there are a lot of noun phrases by employing adjective clauses, clause complex, and elaboration. They act as tools to make the sentences dense and provide information as much as possible in a single sentence. Let us look at how useful they are to establish lexical density throughout the text.

"Butterflies are part of the class of insects in the order Lepidoptera, along with the moths. Adult butterflies have large, often brightly coloured wings, and conspicuous, fluttering flight. The group comprises the large superfamily Papilionoidea, along with two smaller groups, the skippers (superfamily Hesperioidea) and the moth-butterflies (superfamily Hedyloidea). Butterfly fossils date to the Paleocene, about 56 million years ago.

Butterflies have the typical fourstage insect life cycle. Winged adults lay eggs on the food plant on which their larvae, known as caterpillars, will feed. The caterpillars grow, 
sometimes very rapidly, and when fully developed pupate in a chrysalis. When metamorphosis is complete, the pupal skin splits, the adult insect climbs out and, after its wings have expanded and dried, it flies off. Some butterflies, especially in the tropics, have several generations in a year, while others have a single generation, and a few in cold locations may take several years to pass through their whole life cycle.

Butterflies are often polymorphic, and many species make use of camouflage, mimicry and aposematism to evade their predators. Some, like the monarch and the painted lady, migrate over long distances. Some butterflies have parasitoidal relationships with organisms including protozoans, flies, ants, and other invertebrates, and are predated by vertebrates. Some species are pests because in their larval stages they can damage domestic crops or trees; other species are agents of pollination of some plants, and caterpillars of a few butterflies (e.g., harvesters) eat harmful insects. Culturally, butterflies are a popular motif in the visual and literary arts."

Let us consider the marked phrases above. When we look at the italic mark, we can see that the writer adds information from the previous points he mentioned. He directly elaborates the point by adding information after comma and using the word "like" to provide examples. This makes those sentences contain much information.

Looking at the underline mark, we can see the linguistic evidences of how adjective clauses are employed to elaborate a point in order to establish lexical density throughout the text. Adjective clause is one of the most effective way to create density and effectiveness in delivering. It will enable the writer to be efficient in creating sentences as the writer will be able to pile up information in a sentence without having to create numerous sentences to transmit the same amount of information.

Then, let's turn to the phrases marked in bold. Those represent the clause complex connecting logically the major clauses contained in the sentence. Clause complex is defined as a sequence of processes which are logically connected. ${ }^{10}$ The existence of clause complex here makes the text dense, efficient, and effective in delivering the information.

\section{c. Finiteness}

In terms if finiteness, the writer only employed simple form of finiteness. As the language feature of report text, the writer

9 "Butterfly," Wikipedia, August 27, 2018, https://en.wikipedia.org/w/index.php?title=Butterfl y\&oldid=862212825.

${ }^{10}$ Gerot and Wignell, Making Sense of Functional Grammar, 89. 
employed simple present tense and present perfect. They are dominated by to be (is and are) and a few kinds of verb. According to Owen and Leonard, ${ }^{11}$ in a finite clause, the lexical verb must be marked for finiteness. Based on the result, it means that the text is clearly devised to meet the continuum of the most written form of language, language as reflection, very far from the use of action verb as the language accompanying actions. The focus of the writer is to provide dense information by providing long noun phrases connected by simple verb. It is frequent for us to come across very long noun phrase enhanced elaboration and clause complex, and then it is just connected verb "comprises", like in the third sentence of the first paragraph.

\section{Popsci.com (popular science)}

\section{a. Technical Terms}

When we look throughout the text, apparently, the second text looks "more friendly" than the previous one. ${ }^{12}$ The words

\footnotetext{
11 Amanda J. Owen and Laurence B. Leonard, "The Production of Finite and Non-Finite Complement Clauses by Children with Specific Language Impairment and Their Typically Developing Peers," Journal of Speech, Language and Hearing Research 49, no. 3 (2006): 548-71, https://doi.org/10.1044/10902-4388(2006/040).

12 The second text is taken from "Monarch Butterfly Population Revives after Years of Low Numbers," Popular Science, accessed August 27, 2018, https://www.popsci.com/monarch-butterflypopulation-revives-after-years-low-numbers.
}

employed are everyday use which does not block the readers in digesting every single of information that the text provides. There are no special technical terms there which enable common readers to grasp what the text is trying to do.

The absence of special technical terms implies that the writer tried to address common readers as the text is cited from a science magazine. In other words, common readers with adequate knowledge and skill of English will be able to grasp what the text is trying to do. The text does not require special knowledgeability or expertise of the readers in order to digest the provided information. That absence also implies that the tenor between the writer and the reader is more casual compared to the tenor of the previous text. The writer tends to be more friendly and closer to the reader by reporting and telling the readers about what is happening with Monarch butterflies in Mexico. In other words, we can assume that the writer is acting as a news reporter writing news on what is happening with Monarch butterflies recently. $\mathrm{He}$ is addressing common readers.

Inasmuch as the writer is reporting the news about Monarch butterflies, we can assume that the genre of the text is news item. One 
of the features found is the existence of direct speech as the authentic datum displayed in news.

\section{b. Noun phrases}

Merely the same as the previous text, in terms of lexical density, this text is also propertied by adjective clauses and clause complex.

"The amount of monarch butterflies staying in Mexico this winter went up dramatically, increasing in area by 255 percent over last year. Populations of monarchs are measured in acres due to their migration patterns. In Eastern North America, monarchs spread across the United States and Canada in the warmer months, but migrate back to Mexico as winter approaches, clustering back into a small section of forest. Their populations coat the trees and branches so thoroughly that researchers measure the area of land covered instead of trying to count individual butterflies.

This year, the area spreads to cover almost 10 acres, $\underline{a}$ dramatic increase from the 2.8 acres that the butterflies occupied last year. That's optimistic news for researchers hoping to see the population once again meet its 1996 peak of 44.5 acres. The monarch population hit its low in the winter of 2013 and 2014 when the area covered by butterflies was a slender 1.6 acres.

"We are seeing the beginning of success," Daniel Ashe, director of the United States Fish and Wildlife Service, told the New York Times. "Our task now is to continue building on that success." Monarch butterflies continue to face threats, mostly a decline in habitat in Mexico due to illegal logging, and a loss of their preferred food, milkweed, along their route through North America." ${ }^{13}$

\section{Let's consider the italic} marks first. They represent how the writer elaborates a point he just mentioned. Mostly, the writer elaborates them after giving comma. This addition is aimed at establishing effectiveness and efficiency in delivering, instead of making more sentences.

Turning to the underline marks, we can see how adjective clauses are employed. This way is also effective to create effectiveness and to establish lexical density. Adjective clause enables the writer to put more information within a single sentence.

Looking at the bold marks, they represent clause complex employed the writer. Aiming at establishing logical relation among clauses, clause complex is the right way to connect them to create lexical density.

We can see that apparently, the way how to establish lexical density in this text remains the same as the previous text. Both writers employed elaboration or additional information, adjective

13 "Monarch Butterfly Population Revives after Years of Low Numbers." 
clause, and clause complex. The difference is just in terms of word choice or diction.

\section{c. Finiteness}

In terms of finiteness, it seems that the second text also employed similar form if finite by presenting simple present tense. However, as the language feature of news item, it has more stuff to do with the tense. Simple past and present progressive tense are there. Moreover, it is also devised by providing direct speech found in the third paragraph. It means that the second text is richer in terms of the variation of tenses used.

Furthermore, not like the first text which is dominated by to be (is and are), the second text seems to be more varied in using verb. We still find long noun phrases enhanced by adjective clauses and elaboration but they are connected by more variation of verb, compared to the first text. It implies that the second text is more casual and less rigid for its readers than the first one.

\section{Enes-ainenglish.blogspot.co.id (narrative text)}

\section{a. Technical terms}

In this case, we will come to a view that it differs much from the last two we have analysed. Although it is similar to the second text which does not display any special technical terms, the third one seems to have simpler words than those of the last two. When we view this by considering the continuum of written and spoken language, it seems that it will in the middle of the continuum. Although the mode is written text, we can find numerous performative verbs such as say, see, suggest, explain, etc. It implies that the text is devised to get closer to the language accompanying actions.

By looking at how the writer chooses the dictions, we can assume that the writer tried to address English beginner. In this case, it could be children. The writer is a story maker trying to compose a genre of narrative text in order to amuse the reader.

\section{b. Noun phrases}

We are no longer exposed to long phrases enhanced by adjective clause, elaboration, and clause complex. The majority of the sentence use is simple form without any further elaboration of both of subject and complement/ object. The text just elaborates its noun by employing adjective and preposition like those such as, it was my favorited crown; and Kodi (did) saw the crown behind the curtain. For the full text, here it is:

\footnotetext{
"Once upon a time, there were two butterflies, Teri and Roni. They were friends. Teri and Roni had the same crown.
} 
One day, Kodi a frog, saw Teri and Roni quarrelling. "You took it!" said Roni. "No, I did not!" said Teri.

"Hey, what's the matter?" asked Kodi.

"Teri stole my crown!" said Roni. "No, I didn't," said Teri.

"Yesterday, I still had my crown when she came to visit me," said Roni.

"Today I cannot find the crown! Look! She is wearing it!" Roni shouted.

"My mom gave me this crown," Teri explained. Kodi suggested they all go to Roni's house. "Where did you put it?" said Kodi to Roni. "I put it on the table," Roni answered. They didn't find the crown.

"Maybe it fell down." Kodi looked under the table.

Nothing was there.

"It was my favourite crown!" Roni sobbed.

"I didn't steal yours, but if you like it so much, you can have mine," Teri gave Roni the crown.

"It's here!" Kodi saw the crown behind the curtain.

Roni stopped crying, "Thank God, Kodi found it!" "Sorry, Teri, I accused you. I'm a terrible friend!" "It's okay," said Teri." ${ }^{14}$

\section{Looking at the lexical} density, the third text seems not to focus on carrying information by elaborating the noun phrase. It is more focused on telling what is

14 "English Genres: The Two Butterflies," English Genres (blog), August 27, 2018, http://enesainenglish.blogspot.com/2012/02/twobutterflies.html. happening to the actor by displaying various kinds of verbs as the language accompanying actions, remain close to the spoken language form. The nouns positioned as the subject, complement, or objects are simply stated without further elaboration. Most of them stand alone and some are just enhanced by adjective, preposition, or possessive.

By looking at the simple phrases displayed in the text, again, we can assume that the tenor between the writer and the reader is very casual, just like a person telling story to someone else. The writer can be a story maker or even a child having imagination on creating the story. The addressed readers are children who are interested in imaginary story.

\section{c. Finiteness}

As the language feature of narrative text, the writer simply employed simple past tense to report the story. There are also several present progressives occurring in direct speeches used to make the text more interactive to the readers.

Although it is dominated by simple past tense, not like the previous two, this text is equipped with various kinds of verbs showing the actions of the actors 
and actresses. Most of the employed verbs are performative verbs presenting what the actors and actresses do within the story. This is the use of language accompanying actions in which, in the same time, the speakers do what they say.

\section{Conclusion}

A report text of butterflies (the first passage which were taken from Wikipedia) is the most advanced among the three texts. It is equipped with special technical terms addressing special knowledgeable readers. It employs elaboration, adjective clauses, and clause complex to establish lexical density. However, it employs simple form of finiteness compared to other two. It acts as a written language representing language as reflection.

A news item about Monarch butterflies, is less advanced than the first. It is not equipped with special technical terms so it addresses common readers with adequate knowledge of English. It also employs elaboration, adjective clause, and clause complex to establish lexical density. It employs more variation of verbs compared to the previous one which is dominated by to be (is and are).

For the rest, a narrative text about two butterflies; Teri and Roni, is the least advanced one. ${ }^{15}$ It is not equipped with special technical terms and advanced construction of noun phrases so it addresses low-proficiency/ beginner readers of English like children. It employs simple form of sentence and elaborates the noun only by using adjective, preposition, and possessive form. Moreover, it is dominated by performative verbs, not noun phrases, representing the close relation in continuum to the language accompanying action.

Finally, the writers would like to give the suggestion based on the results. It is clear enough for the teachers to get many information and advantage from this study. At this time, literacy should be focus point for the teachers to be selective in taking a text as teaching material that is appropriate with students' level of reading skill. It also helps the teachers for doing building skills, establishing purpose, and fostering motivation during teaching and learning process. This is teachers' time to be creative, selective, and aware to adjust texts based on the students' need. So that, the students can comprehend the texts easily, even, they can be happy to learn.

15 "English Genres." 


\section{Bibliography}

"Butterfly." Wikipedia, August 27, 2018. https://en.wikipedia.org/w/index.p hp?title=Butterfly\&oldid $=8622128$ 25.

Eggins, Suzanne. Introduction to Systemic Functional Linguistics. 2nd ed. London: Continuum, 2004.

"English Genres: The Two Butterflies." English Genres (blog), August 27, 2018. http://enesainenglish.blogspot.com/2012/02 /two-butterflies.html.

Gerot, Linda, and Peter Wignell. Making Sense of Functional Grammar. Cammeray: Antipodean Educational Enterprises, 1995.

Habibullah, Mosleh. "Techniques in Teaching Reading

Comprehension." OKARA: Jurnal Bahasa Dan Sastra 6, no. 2 (2012): http://dx.doi.org/10.19105/ojbs.v6 i2.431.

Hamidah, Nuriyatul. "Story Grammar Strategy: An Approach to Teach Reading Narrative Text." OKARA: Jurnal Bahasa Dan Sastra 10, no. 1 (2016): 44-53. http://dx.doi.org/10.19105/ojbs.v1 0i1.810.

Hinkel, Eli. Teaching English Grammar to Speakers of Other Languages. New York: Routledge, 2016.

"Monarch Butterfly Population Revives after Years of Low Numbers." Popular Science. Accessed August 27, 2018. https://www.popsci.com/monarch -butterfly-population-revivesafter-years-low-numbers.

Owen, Amanda J., and Laurence B. Leonard. "The Production of Finite and Non-Finite Complement Clauses by Children with Specific Language Impairment and Their Typically Developing Peers." Journal of Speech, Language and Hearing Research 49, no. 3 (2006): 54871. https://doi.org/10.1044/109024388(2006/040).

Shanahan, Timothy, Douglas Fisher, and Nancy Frey. "The Challenge of Challenging Text." Reading: The Core Skill 69, no. 2 (March 2012): 58-62.

Sugiyono. Metode Penelitian Kuantitatif, Kualitatif Dan $R$ \& D. Bandung: Alfabeta, 2013.

Thornbury, Scott. How to Teach Speaking. London: Pearson Educational Limited, 2005. 
